<smiles>[CH]C=C</smiles>

\title{
STEROL COMPOSITION OF THREE MARINE SPONGE SPECIES FROM THE GENUS CINACHYRELLA
}

\author{
Gilles Barnathan, ${ }^{*}$ Joseph Miralles, $†$ Jean-Michel Ninkoue, $†$ Alfonso Mangoni, $\ddagger$ \\ ERnesto Fattorusso, $\ddagger$ CECILE Debrtus, $\S$ Nicole Boury-Esnault $\|$ and \\ JEAN-MICHEL KORNPROBST*T
}

*Faculté de Pharmacie-Groupe SMAB-1, rue G. Veil, 44035 Nantes Cedex, France, Tel.: -40.41.28.28; Fax: 40.41.28.09; †Département de Biologie Végétale, Faculté des Sciences, Université Cheikh Anta Diop de Dakar, Dakar, Ś́négal; †Dipartimento di Chimica delle Sostanze Naturali, Via Montesano 49, 80131 Napoli, Italia; §Centre ORSTOM de Nouméa, B.P. AS, Nouméa Cédex, Nouvelle Calédonie; \|Centre d'Océanologie de Marseille, Station Marine d'Endoume, 13007 Marseille, France

(Received 17 February 1992; accepted 18 March 1992)

\begin{abstract}
The hitherto undescribed sterol compositions of three marine sponge species belonging to the genus Cinachyrella are reported: $C$. alloclada and $C$. kükenthali from the Senegalese coast, at two different depths, and $C$. aff. schulzei from the lagoon of Nouméa, New Caledonia.

2. Fourteen free sterols have been identified by GC and GC/MS studies, including the $23,24 \xi$-dimethylcholesta-5,22-dien-3 $\beta$-ol (10) and the rare 24-norcholesta-5,22-dien-3 $\beta$-ol (1).

3. The first compound (10) is reported for the second time in a marine sponge and it was found only in Senegalese sponges collected in shallow waters.

4. Sterol (10) has been isolated by HPLC and identified by NMR techniques.

5. Significant amounts of cholest-7-en-3 $\beta$-ol (7) were also found in the Senegalese sponge species.

6. Apart from these two compounds, the three sponge sterol compositions are found to be very similar.
\end{abstract}

\section{INTRODUCTION}

Marine sterols are associated with the polar lipid fatty acids in membranes. They have been studied for more than 20 years in chemotaxonomic and ecological perspectives and in order to identify novel structures, especially those postulated as biosynthetic intermediates.

Sterols from sponges belonging to the Tetillidae family have been little investigated to date. Sterols of a Cinachyra sp. have been described in a comparative study with several other sponges from New Zealand (Bergquist et al., 1980). More recently, the Mediterranean sponge Cinachyra tarentina was shown to contain three cholest-4-en-3-ones and two cholest4-ene-3,6-diones in addition to three common $3 \beta$-hydroxysterols (Aiello et al., 1991).

In continuing our research on sponge sterols (Sjöstrand et al., 1981; Ayanoglu et al., 1983a and b), we wish to report here the sterol composition of three sponges belonging to the Tetillidae family: Cinachyrella alloclada and $C$. kükenthali that are found on the Senegalese coast in two different zones (in shallow waters and at depths between 15 and 25 meters) allowing a comparative study, and C. aff. schulzei, which was collected from the lagoon of Nouméa, New Caledonia.

We recently reported the phospholipid fatty acids of C. alloclada (Barnathan et al., 1992). The fatty acid compositions of $C$. kükenthali and $C$. aff. schulzei are currently under investigation in our laboratory and it should be noted that $C$. kükenthali is reported herein for the first time in the Eastern tropical Atlantic.

ITo whom correspondence should be addressed.
From a chemotaxonomic perspective, lipid constituents of Tetillidae sponges present a new interest after the recent systematic re-evaluation of this family (Rützler, 1987).

\section{MATERIAL AND METHODS}

\section{Sponges}

All sponge specimens studied belong to the Tetillidae family (Demospongia, Tetractinomorpha, Spirophorida). Sponges from Senegal coastal waters were collected in February 1989, at two different locations: firstly near Joal ( $\sim 100 \mathrm{~km}$ south of Dakar) on the rocky sea shore at low tide, and secondly, around the Madeleine Islands (Dakar) by hand (Scuba) at depths of between 15 and 25 meters.

Cinachyrella alloclada was recently described elsewhere (Barnathan et al., 1992); C. kükenthali Uliczka specimens are yellow, globular sponges, $3-8 \mathrm{~cm}$ in diameter. Their surface is rough and the inhalant openings are located in aquiferous pits (porocalices). The principal skeleton is radial and composed of siliceous spicules, principally oxeas, protriaenes, anatriaenes and spinispires. There is no differentiation of the cortical skeleton. Specimens of $C$. kükenthal are quite similar to $C$. alloclada but porocalices are most often barely visible and this species is characterized by the presence of small, rough or crenulated oxeas. Symbiotic bacteria have been noted in this species (Rützler, 1987). Cinachyrella aff. schulzei Keller (1891). Ref. Spec.: MNHN R 1467 New Caledonia. These sponges were collected by hand (Scuba) in Canal Woodin, at 25-30 meters depth: (size $80 \times 70 \times 60 \mathrm{~mm}$; porocalices $6 \times 3$ to $13 \times 11 \mathrm{~mm}$; hispidation $5 \mathrm{~mm}$; sigmaspires: $22 \mu \mathrm{m}$; oxeas, $4.3 \mathrm{~mm}$; small oxeas, $200-260 \mu \mathrm{m}$; anatriaenes, $5 \mathrm{~mm}$ with studded or knobby clades $-25 \mu \mathrm{m}$, or with normal clades $-35-50 \mu \mathrm{m}$; protriaenes like anatriaenes; several prodiaenes). Another similar species is $C$. hirsuta (Dendy, 1889).

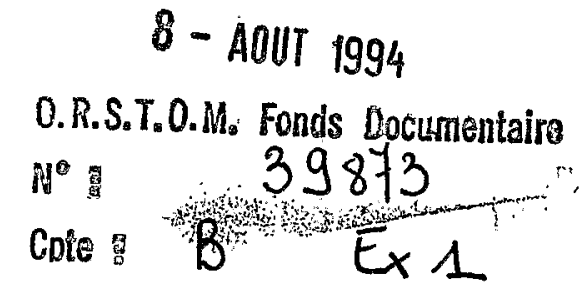


Table 1. Sterol compositions of Cinachyrella species

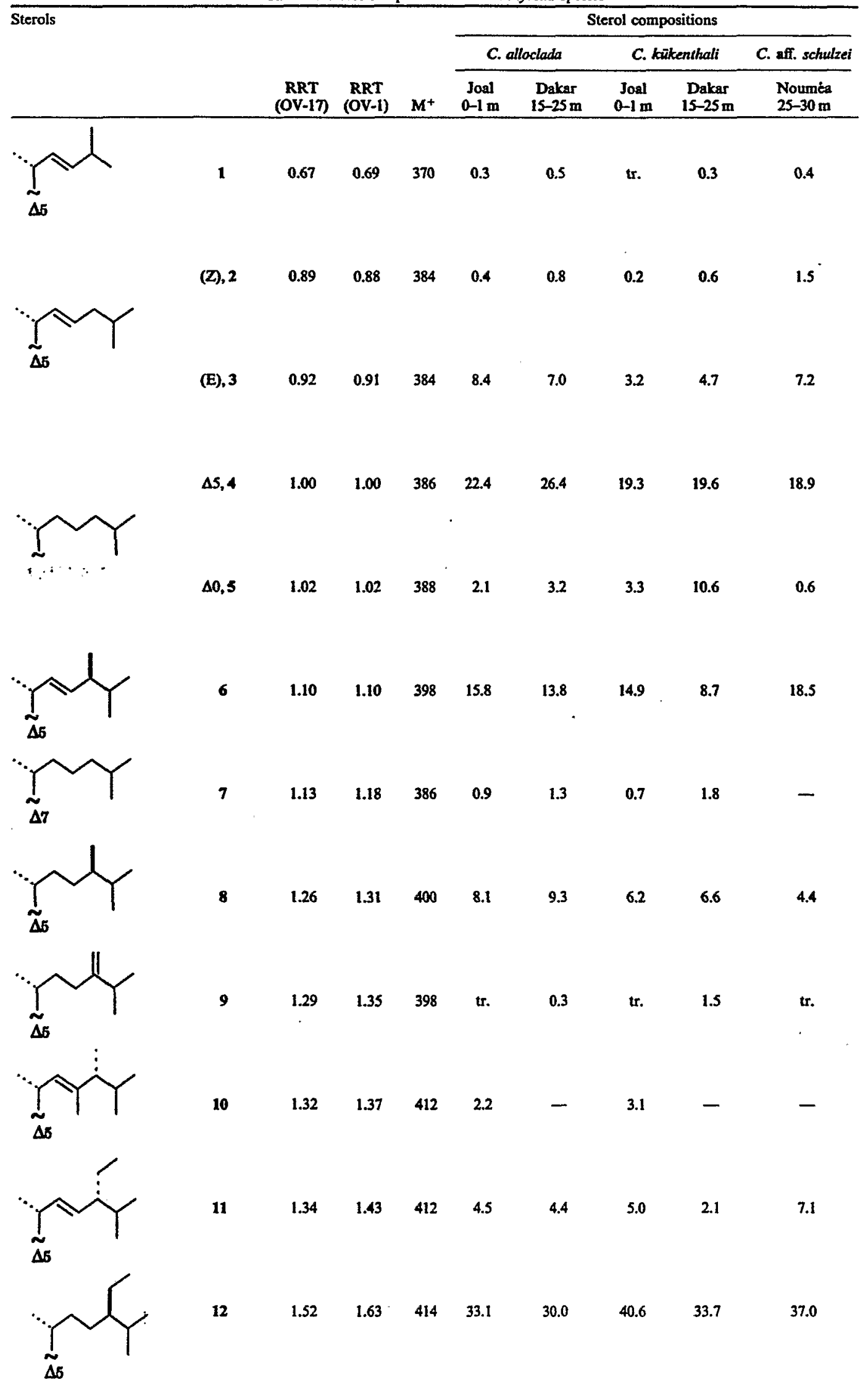


Table 1 continued

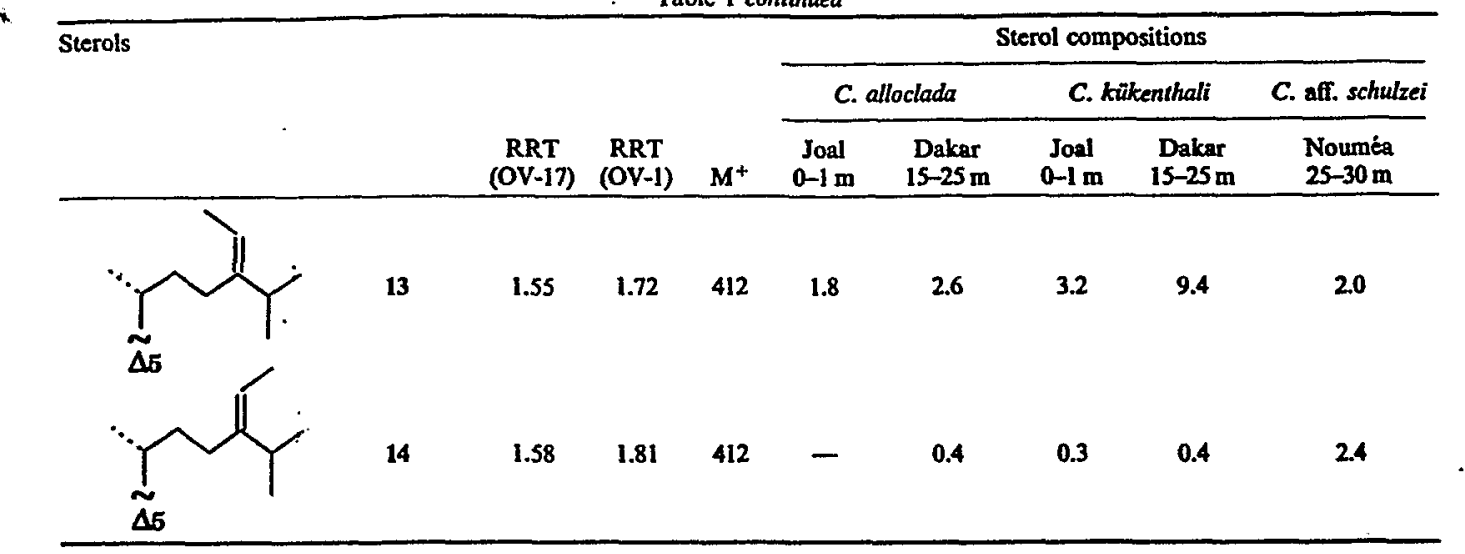

\section{Extraction and isolation of sterol mixtures}

The sponge specimens were washed in sea-water, carefully cleaned, cut in small pieces, ground in a Waring blender with chloroform-methanol $(1: 1, v / v)$ and steeped twice in this mixture for $24 \mathrm{hr}$ (room temperature). The combined extracts yielded the crude total lipids. The neutral lipids were separated from other lipids by column chromatography on silica gel (70-230 mesh) with hexane and chloroform as successive eluents. Polar lipids were separated by further elutions with acetone and methanol. The free sterol fractions, generally obtained among the middle fractions, were combined, concentrated under reduced pressure and the residue chromatographed on a silica gei column (diethylether-hexane 1:1, v/v or dichloromethane-methanol 99:1, v/v as eluents). Yields of different fractions are given in Table 2. The chromatographic fractions were monitored by TLC on HF-254 silica gel plates which were developed using benzene-methanol $96: 4, v / v$ or hexane-diethylether-acetic acid $70: 30: 1, v / v / v$.

\section{$G C$ analysis}

The total sterols were acetylated with acetic anhydridepyridine $(1: 1, v / v)$ for $24 \mathrm{hr}$ at room temperature. The steryl acetates were purified on a silica gel column with mixtures of hexane and increasing amounts of diethylether. The resulting steryl acetates were analyzed by gas-liquid chromatography on silica capillary columns with OV-1 and OV-17 stationary phases $(25 \mathrm{~m} \times 0.32 \mathrm{~mm}$ i.d., $0.40 \mu \mathrm{m}$ phase thickness); hydrogen was used as carrier gas (inlet pressure 0.6 bar, split 5:100); injector and detector temperatures were $285^{\circ} \mathrm{C}$. Analyses were performed with a Carlo Erba 4130 instrument equipped with a FID detector connected to a Spectra-Physics model 4270 numerical integrator. Isothermal analyses were run at $265^{\circ} \mathrm{C}$ in order to determine relative retention time (RRT) of steryl acetates (to cholesteryl acetate). Identifications were based on comparison of GC mobilities with those of known standards and MS data. Relative retention times (Table 1) are linearly correlated with those published by Itoh et al. (1982).
The GC/MS analyses of the steryl acetates were performed on a $12 \mathrm{~m} \times 0.2 \mathrm{~mm}$ i.d. HP 1 column (phase thickness $0.33 \mu \mathrm{m}$ ) with the following linear temperature programming conditions; $150^{\circ}-300^{\circ} \mathrm{C}$ at $7^{\circ} / \mathrm{mn}$; injector $260^{\circ} \mathrm{C}$. The GC chromatograph HP-5890 was coupled with a HP 5989-A mass spectrometer (EI 70 and $20 \mathrm{eV}$ ) equipped with a HP 9000/345 integrator. The mass spectrum of the acetyl derivative of 10 was in good agreement with a previously described spectrum (Kanazawa et al., 1977). The $\Delta 7$ sterol (7) was readily characterized because its acetate produced a molecular ion peak whereas the cholesteryl acetate produced a $(M-60)^{+}$peak (Knights, 1967).

\section{Isolation of sterol (10) from Cinachyrella kūkenthali}

The crude sterol fraction (104 mg) obtained from the specimens of $C$. kitkenthali collected in shallow water along the coast of Joal (Senegal), was fractionated by repeated HPLC, using the following experimental conditions, in the order: (a) column $250 \times 10 \mathrm{~mm}, \mathrm{RP}-18,7 \mu \mathrm{m}$ phase thickness, eluant MeOH; (b) column $250 \times 4 \mathrm{~mm}, \mathrm{RP}-18,3 \mu \mathrm{m}$ phase thickness, eluent n-hexane-EtOAc 9:1. Pure 10 (1.7 mg) was thus obtained, and subjected to 'H-NMR analysis on a Bruker AMX-500 spectrometer in $\mathrm{CDCl}_{3}$ solution. The $500 \mathrm{MHz}$ proton spectrum showed signals at $\delta 5.35$ (m, H-6), 4.88 (bd, $J=10 \mathrm{~Hz}, \mathrm{H}-22$ ), 3.52 (m, H-3), 2.35 (m, H-20), 2.04 (m, H-24), 1.52 (m, H-25), 1.498 (bs, $\left.\mathrm{CH}_{3}-29\right), 1.010\left(\mathrm{~s}, \mathrm{CH}_{3}-19\right), 0.933$ (d, $J=6.6 \mathrm{~Hz}_{2} \mathrm{CH}_{3}-21$ ), 0.928 (d, $J=6.8 \mathrm{~Hz}, \mathrm{CH}_{3}-28$ ), 0.836 and 0.778 (ds, $J=6.6 \mathrm{~Hz}_{2} \mathrm{CH}_{3}-26$ and $\left.\mathrm{CH}_{3}-27\right), 0.709\left(\mathrm{~s}, \mathrm{CH}_{3}-18\right)$. These assignments were in good agreement with those previously published (Kanazawa et al., 1977a).

\section{RESULTS AND DISCUSSION}

The sterol compositions of the three Cinachyrella are presented below, including data for samples from two different depths in the case of the Senegalese sponges (Table 1). Fourteen sterols were identified by

Table 2. Yields of different fractions

\begin{tabular}{lccc}
\hline \multicolumn{4}{c}{ Table 2. Yields of difterent fractions } \\
\hline Sponges & $\begin{array}{c}\text { \% Total lipids } \\
\text { (in sponge) }\end{array}$ & $\begin{array}{c}\text { \%Total sterols } \\
\text { (in total lipids) }\end{array}$ & $\begin{array}{c}\text { \%Total free sterols } \\
\text { (in sponge) }\end{array}$ \\
\hline $\begin{array}{l}\text { C. alloclada } \\
\text { (Joal, 0-1 m) }\end{array}$ & 2.7 & 23.1 & 0.6 \\
$\begin{array}{l}\text { C. alloclada } \\
\text { (Dakar, 15-25 m) }\end{array}$ & 2.9 & 18.5 & 0.5 \\
$\begin{array}{l}\text { C. } \text { kükenthali } \\
\text { (Joal, 0-1 m) }\end{array}$ & 3.1 & 26.8 & 0.8 \\
$\begin{array}{l}\text { C. kükenthali } \\
\text { (Dakar, } 5-25 \mathrm{~m} \text { ) }\end{array}$ & 1.9 & 21.3 & 0.4 \\
$\begin{array}{l}\text { C. aff. schulzei } \\
\text { Noumea, 25-30 m) }\end{array}$ & 1.9 & 17.1 & 0.3 \\
\hline
\end{tabular}


capillary GC and GC/MS as acetyl derivatives. The major component is shown to be clionasterol (12) in all studied samples $(30-40 \%)$ followed by two other major components, namely cholesterol (4) and brassicasterol (6). The sterol composition appears to be very similar for the three Senegalese species and for the Cinachyra sp. from New Zealand, (Bergquist et al., 1980). For the Mediterranean species, Cinachyra tarentina, sterols 4 and 6 were reported as major components. Despite this similarity, these sterol compositions do not provide sufficient information for taxonomic purposes since these sterols are known to be very common in marine invertebrates.

For Senegalese species the sterol distribution was not affected by depth, with the notable exception of 23,24-dimethylcholesta-5,22-dien-3 $\beta$ ol (10) previously reported for the first time in a soft coral (Kanazawa et al., 1974). The sterol 10 was not found in deep water sponges except in a few samples as a trace compound (Barnathan, unpublished observations).

This is the second report of sterol $\mathbf{1 0}$ in a marine sponge, to the best of our knowledge. It was previously reported in the sponge Axinella cannabina as a trace component in a complex mixture of more than 70 sterols (Itoh et al., 1983). The Stanford group has also described the corresponding highly-branched side-chain in sponges, but coupled with modified sterol nuclei; an A-nor nucleus in Teichaxinella morchella (Bohlin et al., 1981) and Homaxinella trachys (Eggersdorfer et al., 1982), and a 19-nor nucleus in Axinella polypoides (Christ and Djerassi, 1983). In addition, the $\Delta 5$ sterol with the same saturated side-chain has been described in the sponge Stelleta conulosa (Zielinski et al., 1983).

The sterol 10 has been described as a major sterol $(19 \%)$, in addition to dinosterol $(20 \%)$ in a marine unicellular alga related to Dinophycese, first harvested at 2 meters' depth (Nichols et al., 1983, 1984). It was found in a diatom (Volkman et al., 1980) and in several species of Coelenterates (Kanazawa et al., $1977 \mathrm{~b})$. Sterol 10 was also identified in a marine dinoflagellate, also associated with dinosterol (12.5\% and $28.7 \%$ respectively) (Nichols et al., 1984). Significant amounts of 10 have been reported in several cultured Zooxanthellae (Kokke et al., 1981; Withers et al., 1982), in addition to gorgosterol (Djerassi and Doss, 1990). Diatoms and dinoflagellates are known to be important components of the phytoplankton and thus to form the foundation of marine food chains. They also occur as symbionts in marine invertebrates. Thus, it seems likely that sterol $\mathbf{1 0}$ is widespread for attached marine animals such as sponges, corals, gorgonians and some mollusks. It has been indicated that the association between marine sponges and Zooxanthellae appears less frequent (Bergquist, 1978). If sterol 10 is provided by plankton it is understandable that this compound was found only in sponges living in shallow waters since sufficient light has to penetrate to sustain photosynthetic processes. This hypothesis is reinforced for Senegalese sponges because of the permanent turbidity of ocean. 24-Norcholesta-5,22-dien-ol-3 (1) is known to occur in Diatoms and has been detected in many marine organisms including marine sponges (Erdman and Thomson, 1972; Kanazawa et al., 1979;
Teshima et al., 1983). It probably originates from dietary planktonic sources.

Another interesting sterol found in several samples of Cinachyrella species is the unusual cholest-7-en$3 \beta$-ol (lathosterol). It has been identified in the sponges Grantia compressa (Edmonds et al., 1977) and Gelliodes fibulata (Kanazawa et al., 1979). Other sponges have been shown to contain large amounts of $\Delta 7$ sterols, especially Agelas mauritania and $A$. oroides (De Rosa et al., 1973; Bergquist et al., 1980; Di Giacomo et al., 1983), although the $\Delta 5$ sterols are the most widely distributed. In addition, sterol 1 and $\Delta 7 \mathrm{C} 27$ sterols were recently shown to occur in several sponge species (Bergquist et al., 1991).

Acknowledgements-We thank Professor C. Levi, Musce National d'Histoire Naturelle, Paris, for diagnosis of the New Caledonian sponge.

\section{REFERENCES}

Aiello A., Fattorusso E., Magno S., Menna M. Pansini M. (1991) Steroids of the marine sponge Cinachyra tarentina: isolation of cholest-4-ene-3,6-dione and (24R)-24-ethylcholest-4-ene-3,6-dione. J. nat. Prod. 54, 281-285.

Ayanoglu E., Kornprobst J. M., Aboud-Bichara A. and Djerassi C. (1983a) Phospholipid studies in marine organisms 4. (2R, 21Z)-2-Methoxy-21-octacosenoic acid, the first naturally occurring $\alpha$-methoxy acid from a phospholipid. Tetrahedron Lett. 24, 1111-1114.

Ayanoglu E., Popov S., Kornprobst J. M., Aboud-Bichara A. and Djerassi C. (1983b) Phospholipid studies of marine organisms: V. New $\alpha$-methoxy acids from Higginsia tethyoides. Lipids 18, 830-836.

Barnathan G., Miralles J., Gaydou E. M., Boury-Esnault N. and Kornprobst J. M. (1992) New phospholipid fatty acids from the marine sponge Cinachyrella alloclada. Lipids (in press).

Bergquist P. R., Hofheinz W. and Osterhelt G. (1980) Sterol composition and the classification of the Demospongiae. Biochem. Syst. Ecol. 8, 423-435.

Bergquist P. R. (1978) Sponges, p. 178. Hutchinson University Library, London.

Bergquist P. R., Karuso P., Cambie R. C. and Smith D. J. (1991) Sterol composition and classification of the Porifera. Biochem. Syst. Ecol. 19, 17-24.

Bohlin L., Sjöstrand U. and Djerassi C. (1981) Minor and trace sterols in marine invertebrates. Part $20.3 \beta$ Hydroxymethyl-A-nor-patinosterol and $3 \beta$-hydroxymethyl-A-nor-dinosterol. Two new sterols with modified nucleus and side-chain from the sponge Teichaxinella morchella. J. Chem. Soc. Perkin Trans. I, 1023-1028.

Christ B. V. and Djerassi C. (1983) Minor and trace sterols in marine invertebrates 47. A re-investigation of the 19-nor stanols isolated from the sponge Axinella polypoides. Steroids 42, 331-343.

De Rosa M., Minale L. and Sodano G. (1973) Metabolism in Porifera-II. Distribution of sterols. Comp. Biochem. Physiol. 46B, 823-837.

Di Giacomo G, Dini A, Falco G., Marino A and Sica D. (1983) Sterols from the sponge Agelas oroides. Comp. Biochem. Physiol. 74B, 499-501.

Djerassi C. and Doss G. A. (1990) Structure and biosynthesis of cyclopropane-containing sterols of marine origin. New J. Chem. 14, 713-718.

Edmonds C. G., Smith A. G. and Brooks C. J. W. (1977) Analysis of sponge sterols as the trimethylsilyl ethers and as the corresponding $5 \alpha-$ and $\Delta 4-3$-keto-steroids using open-tubular gas chromatography-mass spectrometry. J. Chromat. 133, 372-377. 
- Eggersdorfer M. L., Kokke W. C. M. C., Crandell W., Hochlowski J. E. and Djerassi C. (1982) Sterols in marine invertebrates. 32 . Isolation of $3 \beta$-hydroxymethylA-nor-5 $\alpha$-cholest-15-ene, the first naturally occurring sterol with a 15-16 double bond. J. org. Chem. 47, 5304-5309.

Erdman T. R. and Thomson R. H. (1972) Sterols from the sponges Cliona celata Grant and Hymeniacidon perleve Montagu. Tetrahedron 28, 5163-5173.

Itoh T., Tani H., Fukushima K., Tamura T. Matsumoto T. (1982) Structure-retention relationship of sterols and triterpene alcohols in gas chromatography on a glass capillary column. J. Chromat. 234, 65-75.

Itoh T., Sica D. and Djerassi C. (1983) Minor and trace sterols in marine invertebrates. Part 35 . Isolation and structure elucidation of seventy-four sterols from the sponge Axinella cannabina. J. Chem. Soc. Perkin Trans. I, 147-153.

Kanazawa A., Teshima S. I., Ando T. and Tomita S. (1974) Oocurrence of 23,24-dimethylcholesta-5,22-dien$3 \beta-01$ in a soft coral Sarcophytum elegans. Nippon Suisan Gakkaishi 40, 729-731.

Kanazawa A.. Ando T. and Teshima S. (1977a) A new

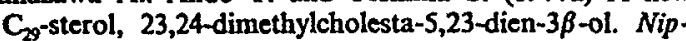
pon Suisan Gakkaishi 43, 83-88.

Kanazawa A., Teshima S. and Ando T. (1977b) Sterols of Coelenterates. Comp. Biochem. Physiol. 57B, 317-323.

Kanazawa A., Teshima S. I. and Hyodo S. I. (1979) Sterols of the sponges (Porifera, Class Demospongiae). Comp. Biochem. Physiol. 62B, 521-525.

Knights B. A. (1967) Identification of plant sterols using combined GLC/mass spectrometry. J. Gas Chromat. 273-282.

Kokke W. C. M. C., Fenical W., Bohlin L. and Djerassi C. (1981) Sterol synthesis by cultured Zooxanthellae; implications concerning sterol metabolism in the host- symbiont associations in Caribbean gorgonians. Comp. Biochem. Physiol. 68B, 281-287.

Nichols P. D., Volkman J. K. and Johns R. B. (1983) Sterols and fatty acids of the marine unicellular alga FCRG 51. Phytochemistry 22, 1447-1452.

Nichols P. D., Jones G. J., De Leeuw J. W. and Johns R. B. (1984) The fatty acids and sterol composition of two marine dinoflagellates. Phytochemistry 23, 1043-1047.

Rützler K. (1987) Tetillidae (Spirophorida, Porifera): a taxonomic re-evaluation. In Taxonomy of Porifera from the N.E. Atlantic and Mediterranean Sea (Edited by Vacelet J. and Boury-Esnault N.), NATO ASI Series, Vol. G13, Springer, Berlin.

Sjöstrand U., Komprobst J. M. and Djerassi C. (1981) Minor and trace sterols from marine invertebrates 29. (22E)-Ergosta-5,22,25-trien-3 $\beta$-ol and (22E,24R)24,26-dimethylcholesta-5,22,25(27)-trien-3 $\beta$-ol. Two new marine sterols from the sponge Pseudaxinella lunaecharta. Steroids 38, 355-364.

Teshima S. I., Kanazawa A., Yamada I. and Tanaka Y. (1983) Sterols of the sponge Tethya amamensis: occurrence of (24E)-24-ethylidene-cholesta-5,7-dienol, (24E)-24-propylidene-cholesta-5,7-dienol, and (24Z)24-propylidenecholesta-5,7-dienol. Lipids 18, 193-197.

Volkman J. K., Eglinton G. and Corner E. D. S. (1980) Sterols and fatty acids of the marine diatom Biddulphia sinensis. Phytochemistry 19, 1809-1813.

Withers N. W. Kokke W. C. M. C. Fenical W. and Djerassi C. (1982) Sterol patterns of cultured Zooxanthellae isolated from marine invertebrates: synthesis of gorgosterol and 23-desmethylgorgosterol by aposymbiotic algac. Proc. natn. Acad. Sci. U.S.A. 79, 3764-3768.

Zielinski J., Kokke W. C. M. C., Tam Ha T. B., Shu A. Y. L., Daux W. L. and Djerassi C. (1983) Isolation, partial synthesis, and structure determination of sterols with the four possible 23,24-dimethylsubstituted side-chains. J. org. Chem. 48, 3471-3477. 